\title{
Gerunds in Greek ${ }^{*}$
}

\author{
Ianthi-Maria Tsimpli \\ Aristotle University of Thessaloniki
}

This paper discusses the properties of Greek V-ondas forms, referred to as gerunds in Holton et al. (1997). It is argued that the clauses in which they occur are adjuncts with a reduced functional structure. Their temporal interpretation will be shown to illustrate the underspecified status of the features of the $\mathrm{V}$-ondas complex as well as the truncated structure of the clause in which it occurs. The position and interpretation of subjects of gerunds will be argued to follow from (a) the inflectional underspecification of gerunds and (b) the pragmatic nature of control.

\section{The data}

Greek V-ondas forms have been referred to in descriptive grammars as gerunds (Holton et al. 1997) or active (present) participles (Bouboulides 1946; Tzartzanos 1946). Consider the following Greek data:

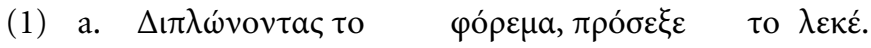
Siplonondas to forema prosekse to leke folding the-Acc dress noticed-3sg the stain 'While folding the dress, he noticed the stain.'

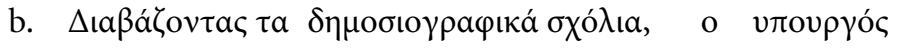

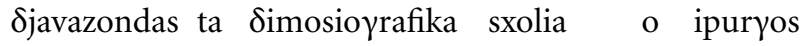
reading the journalists' comments the minister $\theta u ́ \mu \omega \sigma \varepsilon$.

$\theta$ imose got-angry

'As soon as he read the comments, the minister got angry.' 


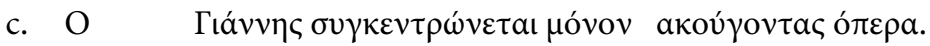

o janis singendronete mononakuyondas opera the-NOM Janis concentrates only listening opera 'Janis manages to concentrate only by/when listening to opera.'

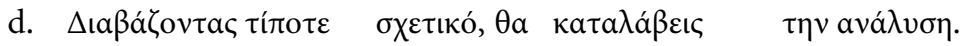
$\delta$ javazondas tipote sxetiko $\theta$ a katalavis tin analisi reading anything relevant will understand-2sG the analysis 'If you read something relevant, you will understand the analysis.'

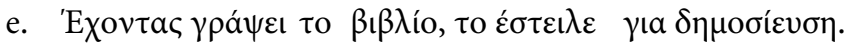
exondas $\gamma$ rapsi to vivlio to estile ja $\delta$ imosiefsi. having written the book it sent-3sg for publication 'Having written the book, he sent it for publication.'

The sentences in (1) illustrate some of the interpretive possibilities of gerunds in Greek sentences; ( $1 \mathrm{a}, \mathrm{b}, \mathrm{e})$ have a temporal reading only, (1c) is ambiguous between a manner and a temporal reading, and (1d) has a conditional reading. ${ }^{1}$ Nevertheless, two properties are shared by all gerunds in the above examples; first, they are all adjuncts and second, they all have a temporal interpretation of the event they denote as contemporaneous with or anterior to the event of the matrix clause, but never posterior. Let us consider these properties in turn.

Greek, unlike English, disallows gerunds in argument positions as shown by the ungrammaticality of the examples in (2):

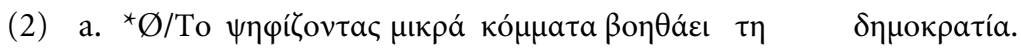

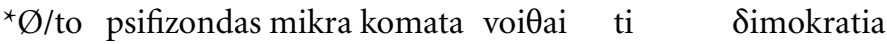
$\varnothing /$ the voting small parties help-3sg the-Acc democracy 'Voting for small parties helps democracy.'

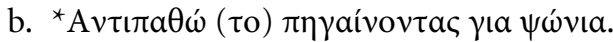
*andipa $\theta$ o to pijenondas ja psonia detest the going for shopping 'I detest going shopping.'

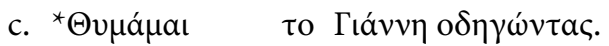

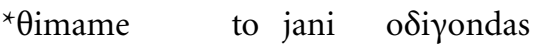
remember-1sg the Jani driving 'I remember Jani driving' (cf. 'I remember Jani while I drive.')

Regarding the ungrammaticality of $(2 a, b)$, note that nominalisation of different types of CP-clauses is very productive in Greek and it consists of the definite article introducing the clause ${ }^{2}$ (Roussou 1991). Thus, wh-clauses, that-clauses, na- (i.e. subjunctive) clauses and if-clauses can all be preceded by 
the definite article. This is obligatory when the clause is in subject position (3a) or dislocated from an object position (3b) but optional in focused position ((3c), focal stress on sinandisi):

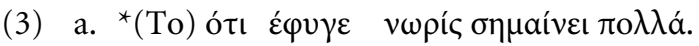

* to oti efije noris simeni pola

the that left-3sg early means many

'That he left early means a lot.'

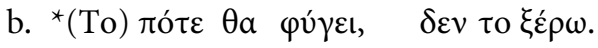

${ }^{*}$ to pote $\theta$ a fiji $\quad \delta$ en to ksero

the when will leave-3sg not it know-1sG

'When he will leave, I don't know.'

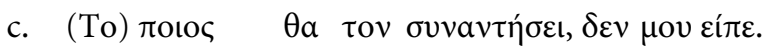

to pjos $\quad \theta$ a ton sinandisi $\delta$ en mu ipe

the who-NOM will him meet-3sg not me told-3sg

'Who will meet him, he didn't tell me.'

The process of nominalisation has been argued to be associated with clauses in argument positions or clauses in peripheral positions which are, in turn, associated with clitics in case-marked positions (Roussou 1991; Tsimpli \& Stavrakaki 1999). Assuming the definite article to be a D element bearing case and resumptive agreement features (Tsimpli \& Stavrakaki 1999) 'nominalisation' is understood to involve a DP introduced by the (expletive) definite article with a complement $\mathrm{CP} .{ }^{3}$ Exceptions to this process of nominalisation are pu-clauses which are complements of factive verbs (Roussou 1994; Varlokosta 1994) and, trivially, all adjunct clauses, since they never appear in case-marked positions. ${ }^{4}$

Since Greek gerunds can only appear in adjunct positions, it could be argued that they can never be nominalised because adjunct positions are not case-marked. However, notice that other adjunct clauses (e.g. (4)), (i) are interpreted as manner, temporal etc., on the basis of the semantic properties of the connective (a C element) which introduces them (e.g. $\pi \rho v v$ prin ('before'),

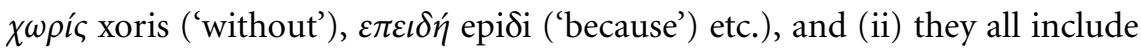
indicative or subjunctive verbal forms but never V-ondas forms, unlike English adjunct clauses:

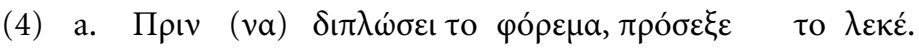
prin na $\delta$ iplosi to forema prosekse to leke before sUBJ fold-3sg the dress noticed-3sg the stain 'Before folding/he folded the dress, he noticed the stain.' 


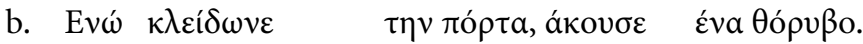

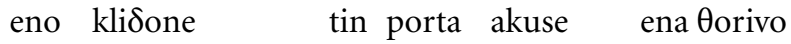 while was-locking-3sg the door, heard-3sg a noise 'While (she was) locking the door, she heard a noise.'}

Greek gerunds are not introduced by connectives, temporal or other. More accurately, although the interpretation of the gerund clause differs in each of the examples in (1), and each of these readings is semantically compatible with a connective, the latter is completely disallowed:

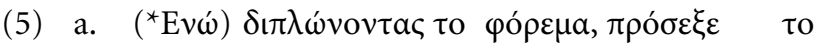
eno Siplonondas to forema prosekse to while folding the dress noticed-3s the $\lambda \varepsilon \kappa \varepsilon$.

leke

stain

'While she was folding the dress, she noticed the stain.'

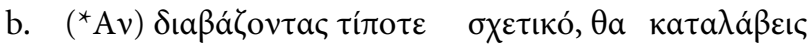
an $\delta$ javazondas tipote sxetiko $\theta \mathrm{a}$ katalavis if reading anything relevant will understand-2sG

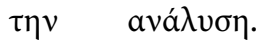

tin analisi

the-ACC analysis

'If you read anything relevant, you will understand the analysis.'

It will be argued that the ungrammaticality of the examples in (5) indicates that the gerund clause is not a CP. If it were, its 'bare' nature, namely the absence of a connective, should in principle leave it underspecified with regard to its argument or adjunct status, as is for example the case with English infinitival or gerund clauses which may appear in either argument or adjunct positions (e.g. purposive clauses as adjuncts). In other words, if the status of this clause was that of a $\mathrm{CP}$, and given that the clause is not introduced by a connective, it should be compatible with the nominalisation process mentioned previously and it could thus be used as an argument, contrary to fact.

As mentioned above, only factive ( $p u-)$ clauses always disallow the definite article but can appear in complement positions since in this position the definite article is not required. They can never appear in subject, dislocated or focused positions. These properties of factive clauses have been attributed to the structural and semantic properties of the complementiser $p u$, namely that it is [definite] (Christidis 1986; Roussou 1994). Roussou argues that the definiteness 
feature is specified on a D head introducing the factive complement. Effectively then, the sole exception to clausal nominalisation is factive complement clauses which are underlyingly DPs. Thus the inability of the gerund clause to appear in argument positions is attributed to its non-CP status. ${ }^{5}$

Consider now the second property that all gerund clauses in the examples in (1) share: they all have a temporal interpretation which denotes an event either simultaneous or antecedent to the matrix event. More specifically, (1a) has the interpretation of the action of 'folding the dress' being interrupted by the event of 'noticing the stain'. The activity in the gerund clause is imperfective, and the two events are contemporaneous. (1b) and (1e) denote an event antecedent to that of the main clause and as such they are construed as perfective. The conditional gerund in (1d) is also temporally construed as antecedent to the event of the main clause. Finally, the 'manner' gerund in (1c) has a simultaneous temporal interpretation with the matrix time. Notice that with the exception of 'perfect' gerunds, e.g. (1e), the simultaneity or the temporally prior nature of the event in the gerund clauses can depend on the situation type of the gerund (e.g. $(6 a \& b))$ and on the aspectual properties of the main verb (e.g. $(6 c-e))$. Consider the contrast below:

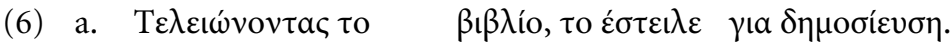
telionondas to vivlio to estile ja $\delta$ imosiefsi finishing the-Acc book it sent-3sg for publication 'As soon as he finished the book, he sent it for publication.'

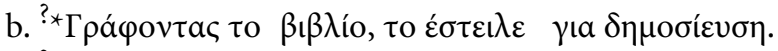
${ }^{? *} \gamma$ rafondas to vivlio to estile ja Simosiefsi writing the book it sent-3sg for publication 'While writing the book, he sent it for publication.'

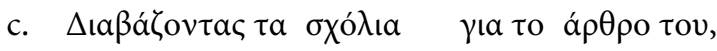
Sjavazondas ta sxolia ja to arӨro tu reading the comments for the article his

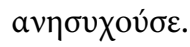

anisixuse was-getting-worried

'While reading the comments on his article, he was getting worried.'

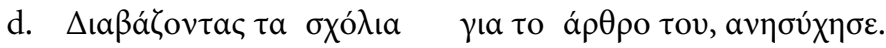
$\delta$ javazondas ta sxolia ja to arӨro tu anisixise reading the comments for the article his got-worried 'Having read the comments on his article, he got worried.' 


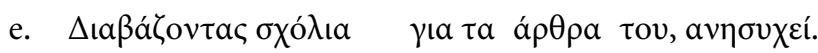
$\delta$ javazondas sxolia ja ta arӨra tu anisixi reading comments for the articles his gets-worried 'He gets worried by reading the comments on his articles/When he reads comments on his articles, he gets worried.'

The only difference between (6a) and (6b) is the accomplishment interpretation associated with the situation type of the verb $\tau \varepsilon \lambda \varepsilon i \omega v \omega$ teliono 'finish' but not with that of the verb $\gamma \rho \alpha \dot{\varphi} \omega$ prafo 'write'. Note that the accomplishment reading is not obligatory with the gerund telionondas as shown by the following example:

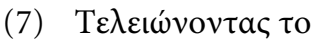

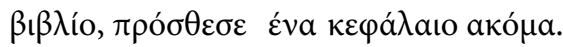
telionondas to vivlio prosӨese ena kefaleo akoma finishing the-Acc book added-3sg one chapter more 'While finishing the book, he added another chapter/As he finished the book, he added another chapter.'

In (7), the interpretation of the event of 'finishing' can be construed either as imperfective, atelic or as perfective in the accomplishment reading. Presumably then, the difference between (6a) and (7) depends on the pragmatic interpretation of the main event in relation to the gerund. Similarly in the examples in ( $6 c \& d)$, the perfective/imperfective reading of the main verb favours a prior or simultaneous temporal interpretation of the gerund respectively, although the lexical choice of the matrix verb is also relevant. It is also noteworthy that the contemporaneity of the two events requires that the gerund in (6c), for example, is interpreted as imperfective progressive, whereas the temporally antecedent reading of the gerund clause in $(6 \mathrm{~d})$ forces a perfective reading on the gerund. Furthermore, (6e) favours a habitual imperfective reading of the gerund, determined again by the present form of the matrix verb.

In morphological terms, the make-up of the Greek gerund consists of the imperfective stem of the verb and the -ondas ending (e.g. $\varphi \varepsilon v y-\omega$ fev $\gamma$-o 'leave-

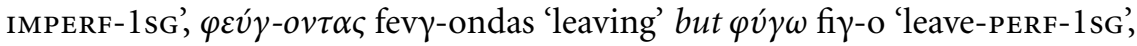

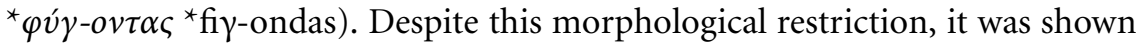
that both the perfective and the imperfective readings are available in some of the above examples. This fact points to two suggestions; first, the property of the imperfective stem to be compatible with both members of the aspectual opposition suggests that the imperfective is the 'unmarked' member of the aspectual paradigm in Greek verbs (cf. Xydopoulos 1996). Second, that the temporal and aspectual interpretation of gerunds is morphologically and 
syntactically underspecified within the gerund clause itself. The temporal interpretation is then derived from the interaction between aspectual features of the main verb (both situation type and viewpoint aspect, Smith 1991) as well as pragmatic conditions on plausibility.

In other words, the antecedent or contemporaneous reading of the gerund clause is not determined by the syntax; instead, the grammar appears to impose constraints only insofar as the situation type of the gerund is concerned. The morphologically imperfective form of the gerund can be overriden in interpretation in case the event it denotes is understood as antecedent to that of the main verb.

I will leave this conclusion without investigating the interpretive possibilities any further since these are not taken to be part of the grammar. However, it is crucial to consider what syntactic implications this conclusion has for the structural representation of gerund clauses in Greek. I turn to this issue in the following section.

\section{Gerunds: CPs or smaller?}

Although the literature on Greek gerunds is not extensive, there is some consensus that Greek gerunds are CPs (Philippaki-Warburton \& Spyropoulos 1999; Tsoulas 1996; cf. Rivero 1994). Philippaki-Warburton \& Spyropoulos discuss subjects in 'manner' gerunds which they analyse as 'controlled'. Their discussion does not include gerunds with a temporal or other interpretation and it is restricted to gerund clauses in sentence-final position. Tsoulas (1996) discusses gerunds with temporal or manner interpretation in positions following and preceding the matrix clause. He also suggests that subjects of gerunds are controlled by an antecedent in the matrix clause. In what follows, I attempt to provide evidence that all Greek gerunds lack the IP and the CP layers.

Considering the alternative aspectual interpretations of gerunds in the examples discussed in the previous section, it was concluded that viewpoint aspect, perfective or imperfective, is not specified on the feature matrix of the gerund form itself. Furthermore, tense is absent in gerunds; the anterior or contemporaneous reading was shown to be derived from the presence or absence of the perfect auxiliary 'have' as well as the temporal and aspectual characteristics of the matrix verb in the absence of the perfect auxiliary (see $(6 a-c)$ ).

Hornstein (1990) argues that English infinitives and gerunds share the property of lacking an $S$ point in the temporal representation. As such, they are 
only specified for Event and Reference time and their interpretation is anchored to the $S / R / E$ points specified in the matrix clause. Although this similarity between infinitives and gerunds holds true for cases in which the gerund is introduced by a temporal connective (while, after, before etc), it does not seem to extend to nominative absolute constructions which lack a temporal connective introducing them (see $(8 \mathrm{~b} \& \mathrm{c}$ ) below). In particular, whereas the temporal reading of an adjunct infinitival is necessarily interpreted as future with respect to the S time of the matrix clause (cf. Stowell 1982, 1992), that of the adjunct gerund lacking a temporal connective is not. Consider the following examples ((8b\&c) adapted from Reuland 1983):

(8) a. We bought the book (in order) to read it on the plane.

b. Elaine's winking at Roddy was/is/has been fruitless, he being a confirmed bachelor.

c. John kept/keeps/has kept walking slowly, the rain drenching the road.

(8b) has a stative interpretation which cannot be shifted by the SOT (sequenceof-tense) rules Hornstein suggests for other cases where the gerund is introduced by a temporal connective. (8c) does not have a future interpretation; the gerund is temporally interpreted as contemporaneous with the tense specified on the matrix verb. Note that although adjunct gerunds are frequently introduced by temporal connectives in English, the nominative absolute construction is the closest equivalent to the distribution of Greek gerunds (see Section 3). We could thus conclude that the infinitive in (8a) differs from the gerunds in $(8 \mathrm{~b} \& \mathrm{c})$ in a way to be specified (see also Stowell 1982 who argues for the non-CP status of gerunds).

Giorgi \& Pianesi $(1991,1997)$ develop a structural analysis of the relations between the $S$ and the $E$ points as specified in a clause. Their analysis is based on the idea that the $\mathrm{S} / \mathrm{E}$ relation is never direct and so it needs to be mediated by $\mathrm{R}$ (Hornstein 1990; Reichenbach 1947). The structural counterpart of this suggestion, together with the Biunique Mapping Principle (Giorgi and Pianesi 1991; cf. the Feature Scattering Principle in Giorgi \& Pianesi 1997), establishes the potential presence of two Tense projections, T1 and T2, T1 expressing the $\mathrm{S} / \mathrm{R}$ relation and $\mathrm{T} 2$ the R/E relation. The Biunique Mapping Principle requires a biunique correspondence between temporal morphemes and T-relations. It is interesting to note that the presence of the two tense projections is found in periphrastic tenses, e.g. the passato prossimo in Italian, where T2 hosts the participle and specifies the R/E relation whereas $\mathrm{T} 1$ hosts the auxiliary and specifies the $S / R$ relation. In the present tense, neither tense projection is 
available given the lack of independent morphological realisation of the present tense morpheme. Thus, the BMP is compatible with the absence of tense projections in the clause structure.

Leaving aside important details of this analysis, it is worth pointing out that aspectual information is found in T2, i.e. the projection hosting the participle in, for example, present perfect forms (cf. Belletti 1990), although Giorgi \& Pianesi (1997) claim that T2 is a temporal projection, thus distinguishing between perfect/non-perfect, a tense difference, and perfectivity/imperfectivity, an aspectual difference (cf. Comrie 1976).

Going back to Hornstein's claim that gerunds, like infinitives, lack an S point, this suggests that the projection responsible for establishing the S/R relation, namely T1 in Giorgi \& Pianesi's analysis, may be missing. Notice further that Hornstein distinguishes between gerunds introduced by temporal connectives and finite, temporal, adjunct clauses introduced by the same connectives, the difference shown in the examples below (Hornstein's examples):

(9) a. John will leave after finishing/having finished the review.

b. John played well after Harry grounded out.

According to Hornstein, the temporal structure of (9a) is derived by assuming that the gerund lacks an S point, thus leaving unspecified an S/R relation, and by mapping the R point of the gerund clause to the matrix R. (9b), on the other hand, involves the association of both the $S$ and $R$ points of the finite adjunct clause to those of the matrix clause. Thus, finiteness is the crucial difference between (9a) and (9b), the former but not the latter lacking an S point. Notice further that Hornstein does not attribute any special formal function to the connective itself although his representation in (10) includes a temporal connective:

(10) (Hornstein 1990:43)

$\left[\mathrm{S}_{\mathrm{S}} \ldots \mathrm{TNS}_{1} \ldots\left[_{\text {adjunct }} \mathrm{TC}\left[\mathrm{S} \ldots \mathrm{TNS}_{2} \ldots\right]\right]\right.$, where $\mathrm{TC}$ is a temporal connective e.g. when or after.

Since the RTC (Rule for Temporal Connectives) involves associating the S and R points of the adjunct and the matrix clause without any special reference to the connective itself, the derived tense structures of sentences like 'John came as Harry arrived' and 'John came after Harry arrived' are identical (Hornstein 1990:47). Hornstein acknowledges this by suggesting that somewhere in the temporal representation the features of the connective should be specified, since these features together with the tense of the sentential adjunct modify the matrix clause (Hornstein 1990:203). The contribution of the connective to the 
temporal interpretation is determined by its lexical semantic features. Thus, although the sentences mentioned above involve the same derived tense structure, the lexical difference between as and after should be relevant at the level where the complete interpretation of the sentence is assigned. Moreover, the difference between gerunds that are introduced by connectives, and those that are not (cf. (9a) and ( $8 b \& c)$ ) is also left to be accounted for independently. Hornstein considers this level of interpretation to be potentially outside the grammar itself, since pragmatic factors are also responsible for the differentiation between temporal structures that the syntax of tense he proposes leaves underspecified. Furthermore, the distinction between $(9 a \& b)$ where both temporal adjuncts are introduced by connectives, their difference being only in the finiteness of the adjunct clause, is accounted for at the level of syntax, where the $S / R / E$ relations are supposed to be specified.

Recall that Greek gerunds cannot be introduced by connectives of any kind (temporal, prepositional etc.). Furthermore, they seem to be compatible with a contemporaneous or anterior temporal interpretation but never a posterior one (see previous section). In other words, it is impossible to derive an interpretation whereby the event denoted by the gerund is temporally posterior to that of the matrix clause (i.e. something equivalent to the English sentence John ate before leaving). The restricted interpretations of Greek gerunds should thus be attributed to the lack of connectives introducing them.

Leaving aside for the moment the derivation of the two readings, the simultaneous and the anterior, the absence of connectives was argued to suggest that the status of the gerund clause in Greek is not a CP (see Section 2). As far as English connectives are concerned, it has been argued that they appear in the C position (Reuland 1979, among others). As mentioned in the previous section, Greek connectives necessarily introduce subjunctive or indicative complements, i.e. structures including verbal forms marked for agreement and more or less specified tense forms, depending on the mood specification of the clause. The choice between subjunctive and indicative complements depends on the selection requirements of the connective itself. Thus, the absence of both tense and agreement specification on gerunds, as well as their incompatibility with a connective can be argued to indicate that their status is not that of a CP.

It has already been shown in Section 1 that gerunds resist nominalisation and in this respect they are 'marked' compared with any other CP (with the exception of factives; see above). Furthermore, Greek gerunds lack any nominal properties unlike passive ( $-\mu \varepsilon ́ v o \varsigma$-menos) participles or other nominals derived

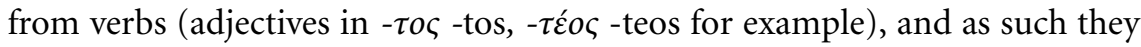


cannot be assumed to be nominal in nature (see also Tsoulas 1996). Further evidence for the suggestion that gerund clauses are not CPs comes from the fact that wh-and focus-movement to initial position are impossible, as shown by the examples below (cf. Joseph 1985; Tsoulas 1996):

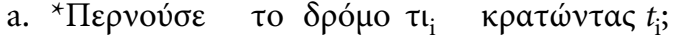 ${ }^{*}$ pernuse to $\delta$ romoti $i_{i}$ kratondas $t_{\mathrm{i}}$ was-crossing the street what holding

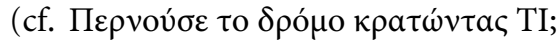
Pernuse to Sromo kratondas

'He was crossing the street holding what?'

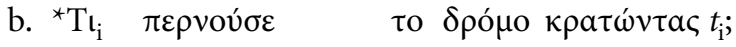
${ }^{*} \mathrm{t}_{\mathrm{i}}$ pernuse to $\delta$ romo kratondas $t_{\mathrm{i}}$ ?
what was-crossing-3sg the street holding

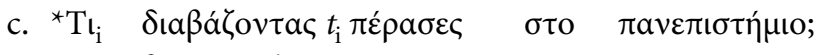

${ }^{*} \mathrm{ti}_{\mathrm{i}} \quad \delta$ javazondas $t_{\mathrm{i}}$ perases sto panepistimio

what reading entered-2sG to-the university

'Reading what, did you enter the university?'

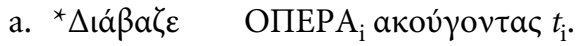
${ }^{\star}$ Sjavaze OPERA $_{\mathrm{i}}$ akuүondas $t_{\mathrm{i}}$
was-reading opera listening
'He was reading while listening to OPERA.'

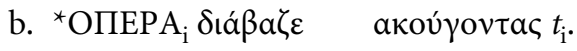

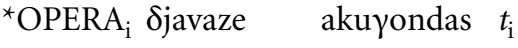
opera was-reading listening
'It was opera that he was listening to while reading.'

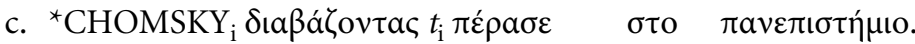
${ }^{*} \mathrm{CHOMSKY}_{\mathrm{i}} \delta$ javazondas $t_{\mathrm{i}}$ perase sto panepistimio
Chomsky reading entered-3sg to-the university
'It was by reading Chomsky that he entered the university.'

The adjunct status of gerund clauses can account for the impossibility of longmovement in (11b) and (12b) but local movement is also impossible within the adjunct clause. ${ }^{6}$ Both types of movement are supposed to involve operator movement to SpecCP/SpecFP (Agouraki 1990; Tsimpli 1990, 1995, 1998). The ungrammaticality of these examples constitutes further evidence for the absence of the relevant positions in the clause structure. Furthermore, note that topics and dislocated elements are also disallowed in gerund clauses: ${ }^{7}$ 
(13)

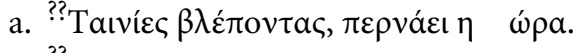
?? tenies vlepondas pernai i ora
films watching passes the time
'Time passes by watching films.'

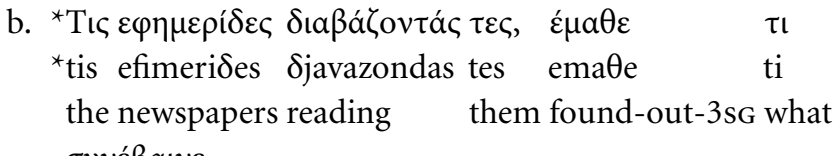
бuvéßaıve.
sinevene
was-happening

'Reading the newspapers, he found out what was happening.'

Assuming that the position for topics and dislocated elements is beyond the IP layer (Philippaki-Warburton 1985; Tsimpli 1990; Anagnostopoulou 1994; Alexiadou \& Anagnostopoulou 1998), the marginal status of the above examples is compatible with the suggestion that these peripheral positions are absent in gerunds. ${ }^{8}$

Summarising the discussion so far, it has been shown that Greek gerunds (a) resist nominalisation, (b) cannot be introduced by connectives, (c) disallow operator-movement and (d) lack the $\bar{A}$-non-Operator positions. These properties suggest that gerunds are not CPs. Adapting Hornstein's claim regarding the absence of an $\mathrm{S}$ point to the structural representation of the $\mathrm{S} / \mathrm{R}$ relation as the absence of a tense projection (T1 in Giorgi and Pianesi's 1991 terms), gerunds are also argued to lack the TP projection which includes Tense, either dependent or independently marked, and subject agreement features (assuming AGR features to be specified on T rather than on a separate projection (Chomsky 1995)).

The next question concerns the representation of other functional projections, namely $\mathrm{T} 2$ or otherwise put, the projection that represents the R/E relation in the structure of the clause. Recall that, as shown in Section 2, Greek gerunds, and in particular the non-perfect ones, are underspecified for both aspect and tense. Regarding aspect, it was suggested that both the perfective and the imperfective readings can be derived in gerunds with the proviso that these readings are compatible with the situation type of the verb. The aspectual interpretation stems from the combination of the temporal and aspectual properties of the matrix verb as well as the pragmatic plausibility of the temporal sequence between the matrix and the event of the adjunct clause (see, for example, the sentences in (5)).

There is, however, one context in which anteriority of the event denoted by the gerund is unambiguously derived on the basis of the perfective interpretation 
expressed by the morphological properties of the gerund clause. Specifically, in perfect gerunds of the type exondas $V$ (perf) ('having V'), the perfective interpretation is unambiguous, and the anterior reading of the event in the adjunct clause is imposed:

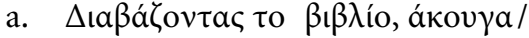
ákovøa

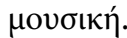

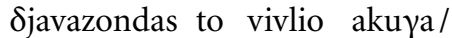
akusa
musiki
reading the book was-listening-1sG/listened-1sG music
'While reading the book, I was listening to music./After reading the book, I listened to music.'

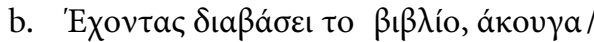
ákovøa exondas Sjavasi to vivlio akuүa/ akusa having read the book was-listening-1sG/listened-1sG

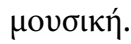
musiki
music
'Having read the book, I was listening to music/I listened to music.'

(14a) shows that the contemporaneous or the anterior reading of the gerund are determined by the aspectual properties of the matrix verb. In (14b), no ambiguity arises with respect to the gerund. I will assume that the perfective reading of the perfect gerund is determined by the perfective non-finite form $\delta \iota \alpha \beta \alpha$ á Sjavasi (Tsangalidis 1999). ${ }^{9}$ Smith (1991) argues that the English perfect is based on the combination of the auxiliary have with a verb specified for either progressive or perfective viewpoint aspect. Thus, in English there are two perfect forms distinguished in terms of aspectual characteristics, i.e. have been going/have gone. The anteriority effect is available in both cases, since it is the result of the composition of have + verb ${ }^{10}$ (cf. Hornstein 1990). In Greek, only one aspectual option is available in the perfect, the perfective. Anteriority is again assumed to be derived compositionally.

Considering the specification of the E/R relation, I have independently argued (Tsimpli 1992/1996) that aspectual properties of both the situation and viewpoint types are represented in $\mathrm{V}$. The $\mathrm{E}$ point is thus present in the $\mathrm{V}$ node as the specification for situation and viewpoint aspect. ${ }^{11}$ In non-perfect gerunds, it was shown above that viewpoint aspect remains underspecified; hence, the $\mathrm{E}$ position on $\mathrm{V}$ is only specified for the situation type lexically defined on the verb.

Insofar as the $\mathrm{R}$ point is concerned, we need to consider perfect gerunds first. In this case, the $\mathrm{E}$ position on $\mathrm{V}$ is specified for both viewpoint (i.e. perfective) and situation type aspect. In addition, the presence of exo ('have') in 
the gerund form in combination with the verb is responsible for the $\mathrm{E} / \mathrm{R}$ relation, the event being anterior to reference time $\left(\mathrm{E} \_\mathrm{R}\right)$. However, in the absence of tense, the $S / R$ relation is unavailable, hence the requirement for mapping the $\mathrm{R}$ point of the gerund clause to that of the matrix, which in turn is linked to $\mathrm{S}$, via $\mathrm{T} 1$ in the matrix clause. We can thus conclude that perfect gerunds include a functional projection above $\mathrm{vP} / \mathrm{VP}$, with features expressing the E/R relation. Note that unlike Giorgi \& Pianesi's account, the suggestion here is that this is not a tense projection but a functional projection relating reference time with the event, i.e. aspectual features. The auxiliary 'have' moves from the V1 (Aux) position to this projection and is co-indexed with the main verb to denote the compositionality of the $\mathrm{R} / \mathrm{E}$ relation:

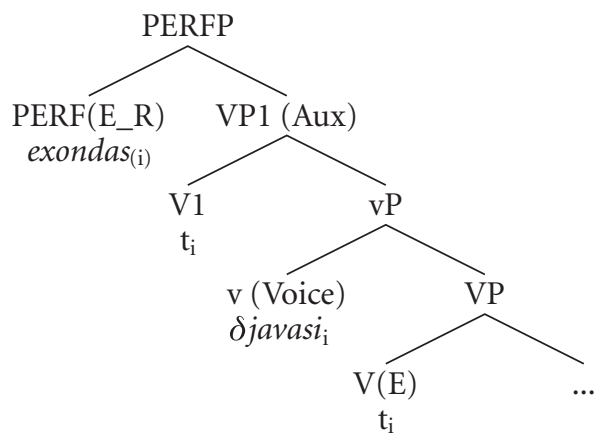

The structure in (15) indicates that exondas appears in the PerfP which instantiates the E/R relation, the implication being that all clauses including perfect tenses structurally represent the $\mathrm{E} / \mathrm{R}$ relation, in accordance with the Biunique Mapping Principle. ${ }^{12}$

Turning now to non-perfect gerunds, the motivation for the PerfP is absent, if the BMP is correct (but see note 9). This implies that these gerunds include only an E point which is mapped onto the $\mathrm{E}$ point of the matrix clause, whereas $\mathrm{R}$ and $\mathrm{E}$ are specified in the matrix clause only. According to this reasoning, we would expect the anteriority or simultaneity of the event denoted by the gerund in relation to the matrix clause to be uniquely specified by the temporal and aspectual features of the matrix verb. This was shown to be false in examples such as (6a) and (7) repeated here for convenience:

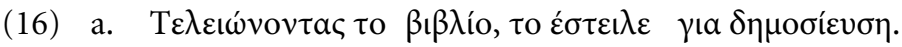
teljonondas to vivlio to estile ja $\delta$ imosiefsi finishing the book it sent-3sg for publication 'After finishing the book, he sent it for publication.' 


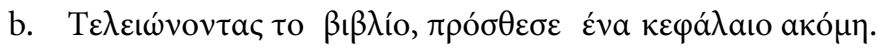
teljonondas to vivlio prosӨese ena kefaleo akomi finishing the book added-3sg one chapter more 'While finishing the book, he added another chapter./Having finished the book, he added another chapter.'

What the examples in (16) show is that, although in both (a\&b) the matrix verb is past, perfective, and the gerund clauses identical, the interpretive possibilities are not fully determined, presumably due to pragmatic factors. It is thus more plausible to assume that temporal interpretation is not uniquely determined on the basis of a mapping between the embedded and the matrix $R$ points. If that was the case, the interpretation should be uniquely determined at the sentence level, similarly with the analysis suggested for the perfect gerund. It is thus more plausible to suggest that the $\mathrm{R} / \mathrm{E}$ relation in the gerund clause remains unspecified (i.e. either E__R or E,R) for two reasons: first, the lack of fully specified aspectual features (the E point) and secondly, the absence of the perfect auxiliary which together with the lack of finiteness renders the event of the gerund clause open to two interpretations, the anterior or the simultaneous, subject to properties of the matrix clause. The implication is that structure (15) is available in non-perfect gerunds too, albeit with unspecified features both on $\mathrm{E}$ (where underspecification may be a more appropriate term) and on $\mathrm{R} .{ }^{13}$ The mapping between the gerund and the matrix clause is as suggested for perfect gerunds, the difference being that lack of specification leaves the possibility for choosing between two structurally available interpretations, on pragmatic grounds.

The question we need to address at this point is what prevents the temporal interpretation of the event in the non-perfect gerund clause as being posterior to that of the matrix. In other words, if the E/R relation remains unspecified in the syntax, the R_E interpretation should also be possible, contrary to fact.

In the absence of connectives introducing gerunds in Greek and the given absence of temporal specification in the non-perfect gerund, the only possibility for the derivation of a posterior reading is a modal, hence future, reading for the gerund. ${ }^{14}$ Note, first, that gerunds are never ambiguous with regard to the assertive or non-assertive reading. In other words, the equivalent of an ambiguous structure like John left before hitting someone, where the before-clause may either be asserted or not (Hornstein 1990), is not found. This may stem from the fact that gerund forms are, probably, the only forms in Greek which never allow a modal, and hence future-oriented, interpretation. ${ }^{15}$ It is standardly assumed that modal operators, depending on their nature, are represented in $\mathrm{T}$ or C positions in the clause structure (cf. Roussou 2000). In view of the suggestion 
that neither of these positions is present in gerunds, the absence of a modal reading is predicted. If this line of reasoning is on the right track, the futureshifted interpretation of the event in the adjunct clause is excluded on the basis of the absence of the modal interpretation. ${ }^{16}$ Given that other tense options are unavailable too, the posterior reading is excluded.

To summarise the discussion so far, it has been argued that gerunds lack both a CP and a TP1 projection where features of focus and wh-, on one hand, and tense and modality, on the other, would be specified, respectively. On the basis of their temporal interpretive possibilities both perfect and non-perfect gerunds are shown to include a functional projection including aspectual features and the $[ \pm$ perfect $]$ feature where the verb or the auxiliary 'have' move to. Aspectual features are primarily specified in the E position on the $\mathrm{V}$ and these include both situation type and viewpoint aspect. Non-perfect gerunds are underspecified with regard to viewpoint aspect as they seem to be compatible with the perfective or the imperfective reading depending on the properties of the matrix verb as well as pragmatic conditions.

The structure suggested in (15) was motivated by inflectional properties and the interpretive possibilities of gerunds. However, the internal syntax of gerunds in relation to the nature and the position of subjects has not been addressed as yet. In the following section, it is argued that the structural properties of gerunds offer some insight into the issue of the syntactic realisation of subjects in Greek.

\section{Subjects of gerunds}

Greek gerunds allow for a null subject or an overt subject marked for nominative case. Consider the examples below:

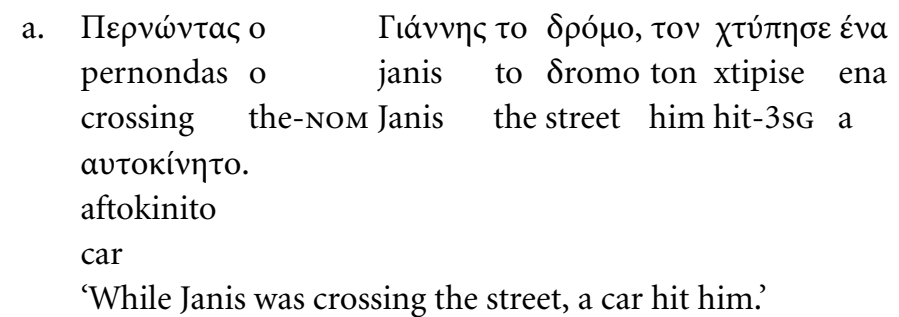




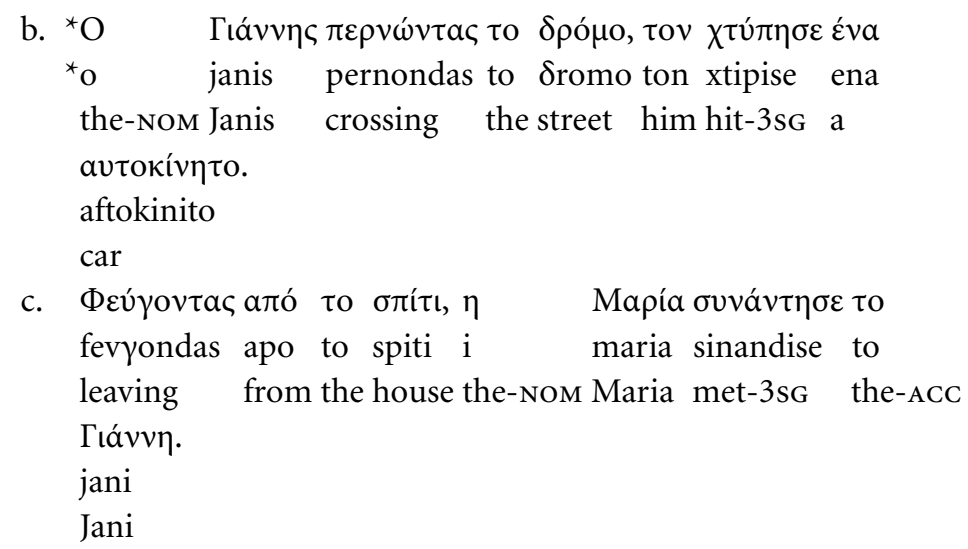

'As soon as she left home, Maria met Jani.'

Example (17a) shows that an overt nominative subject, distinct from the subject of the matrix clause, is possible in the adjunct clause. (17b) differs from (17a) only in the position of the subject of the gerund; it appears that preverbal subjects are disallowed in a gerund clause (cf. Rivero 1994). (17c) shows that null subjects are also possible subjects of gerunds despite the absence of agreement which is standardly assumed to identify the pro subject. The lack of agreement inflection has led Philippaki-Warburton \& Spyropoulos (1999) and Tsoulas (1996) to assume that the subject of a gerund is PRO. It is worth noting that in the absence of infinitives in Greek, gerunds would be the only verbal contexts which would have a PRO subject (cf. Terzi 1992).

The data in $(17 \mathrm{a}-\mathrm{c})$ are interesting insofar as the structural realisation of subjects in gerund clauses is concerned. Needless to say, the default option for co-referentiality between the matrix subject and that of the gerund is for both to be null or one to be null and the other overt, provided the thematic structures of the matrix and the gerundive predicate match (see below). The possibility of having either a null or an overt nominative subject is consistent with the behaviour of subjects in null subject languages in general.

There are however some problems with assuming that this is another instance of the null subject option. First, unlike all other contexts where null subjects are possible in Greek, gerund forms lack agreement morphology which renders identification of the null subject impossible via the local agreement configuration. Secondly, in embedded null subject contexts the reference of the null subject is not restricted by the matrix clause even when the embedded clause is the subjunctive complement of a control verb (Philippaki-Warburton 1987; Philippaki-Warburton \& Catsimali 1999). In gerunds, the default option 
is coreference between the two subjects. Thirdly, the possibility of a preverbal subject is usually available as an alternative option in matrix and embedded clauses, although this is analysed as a topicalised element (Philippaki-Warburton 1985; Tsimpli 1990; Alexiadou \& Anagnostopoulou 1998). Finally, both indicative and subjunctive clauses allow for both referential and expletive subjects. Gerunds, on the other hand, disallow expletive (null) subjects as shown by the following examples: ${ }^{17}$

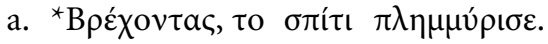
${ }^{*}$ vrexondas to spiti plimirise
raining the house was-flooded

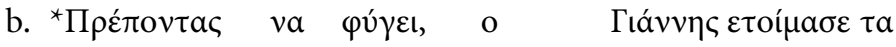 * prepondas na fiji o janis etimase ta must-GERUND subJ leave-3sg the-NOM Janis prepared the

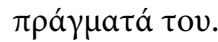 praymata tu things his

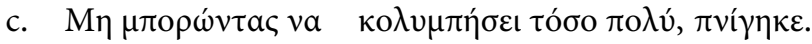 mi borondas na kolimbisi toso poli pnijike not being-able subj swim-3sg so much drowned-3sg 'Not being able to swim, he drowned.'

Impersonal modal verbs as well as weather verbs do not form gerunds. (18c) shows that the ambiguous modal verb bori ('be able'/'be possible') can only appear in the first reading, where the subject is referential, and not in the impersonal form. This shows that the reason for the ungrammaticality cannot be morphophonological but syntactic, semantic or a combination of both. Notice that English gerunds allow for expletive subjects as shown by the following examples (examples from Safir 1985):

(19) a. (It) *being obvious that John was late, we decided to go to the movies.

b. (It) *seeming that the king had been executed, anything appeared possible.

c. ${ }^{\star}$ Before (it) seeming that John was late, a big birthday party was planned.

d. While ( ${ }^{\star}$ he/him) munching on a fig, John broke a tooth.

(19b\&c) show that the expletive in gerunds not introduced by connectives is necessary for the grammaticality of the sentence whereas when the connective is overt, the sentence is ungrammatical. (19d) shows that overt subjects in gerunds introduced by connectives are ungrammatical regardless of referentiality. 
The data in $(19 a-c)$ have been argued to suggest that there cannot be expletive PRO, and given that the null subject of a gerund clause needs to be controlled, the obligatory presence of the overt expletive is accounted for ${ }^{18}$ (cf. Rizzi 1982; Safir 1985). If we extend this analysis to the Greek data in (19) there is good reason to believe that the null subject of gerunds in Greek too is a PRO which, given that it requires control, cannot be expletive.

Notice, however, that there are cases where an expletive subject may be allowed in Greek gerunds:

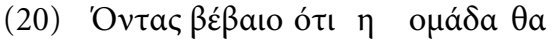

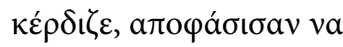

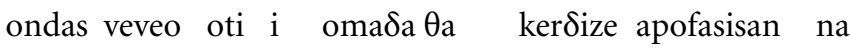
being certain that the team would win decided-3PL subj

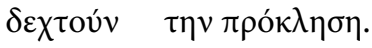
Sextun tin proklisi accept-3PL the challenge

'Being certain that the team would win, they decided to accept the challenge.'

There is a difference between this structure and the ungrammatical ones in (18). In particular, the difference has to do with the fact that (20) resembles English extraposition structures in which the embedded clause is the thematic argument of the verb, unlike true expletive structures where no such coindexation with a thematic subject can take place. If this is correct, then the ungrammaticality of the Greek examples in (18) is not related to the categorial nature of the subject (PRO or pro) but to the absence of a thematic subject.

With regard to the ungrammaticality of ( $18 \mathrm{~b}$ ) note that modal gerunds are ungrammatical in English too; assuming that modals are necessarily finite elements in English and that gerunds lack a tense/modal realisation, the absence of gerund modals is unsurprising. Greek modals are restricted in terms of tense and aspectual marking. They appear only in the imperfective form and as such they can only form the present and the imperfect tenses (e.g. prepi/eprepe (must-3sg/must-past-3sg). The incompatibility of impersonal modals with the gerund form cannot then be due to morphological reasons; instead it is suggested that modals appear in an independent clause, from the following subjunctive clause, which has been argued to select a tensed proposition as its complement (Roussou 1999). The construction is thus not similar to the extraposition structure suggested for $(20)$; $(18 \mathrm{~b})$ presupposes an expletive subject in the matrix clause where the modal verb appears and the embedded clause is not a thematic subject but a complement proposition. 
According to this line of reasoning, the question is the following: Is the unavailability of predicates with expletive subjects in Greek gerunds due to the thematic requirement on subjects of gerunds, or is it due to the structural position that expletive subjects occupy in finite clauses, which is arguably unavailable in gerunds? The first possibility, if true, would have to further account for the distinction between Greek and English, since English allows non-thematic subjects for gerunds. I will thus pursue the second alternative which invokes a structural deficiency in gerund clauses.

As far as Greek subjects and subject positions are concerned, it has recently been argued by Philippaki-Warburton \& Spyropoulos (1999) and Spyropoulos (2000) that the Greek subject is a discontinuous element including the thematic subject position in VP and the EPP position in SpecTP where formal features of the subject are represented in the form of a null subject clitic (cf. Horrocks 1994). The authors assume that overt postverbal thematic subjects appear in the position of merge, namely SpecVP where pro subjects may also appear. Expletive subject clitics appear in the EPP position, the motivation being the predication requirement on the predicate.

Deviating partly from this claim and following Chomsky's minimalist assumptions, I will assume that the EPP position necessarily requires a tense/ modal structure (even if defective), namely SpecTP (TP1) bearing subjectagreement features too. When the subject is thematic, it merges in the SpecvP/ VP depending on the transitivity of the verb (Chomsky 1995, 1998). If there is a tense/modal structure, then the EPP position also projects licensing a pro subject, co-indexed with the thematic position. Thus, in Greek the EPP position projects provided there is a TP1 since the relevant agreement features are found in the $\mathrm{T}$ position. These are responsible for identification of the null subject as required by Full Interpretation. With regard to the differences between the lower and the higher positions, I will assume that T/AGR may also bear a topic (p-) feature which thus implies that an additional specifier can project when (overt) subjects are represented as topics (cf. Chomsky 1998). The implication is that when overt thematic subjects appear in preverbal position, they are topics moved from the lower position (cf. Philippaki-Warburton 1985; Tsimpli 1990; Alexiadou \& Anagnostopoulou 1998).

However, preverbal subjects are associated with additional restrictions. For example, generic and nominalised clausal subjects necessarily appear in the preverbal position. I assume that in these cases the embedded thematic position does not project in the absence of a referential interpretation of the subject, and merge takes place in the preverbal position. If this is correct, expletive subjects 
also merge directly in this position. In such cases, the EPP-feature of T/AGR is responsible for the merge of these categories of subjects, unlike thematic subjects where movement motivated by the topic-feature of Tense takes place. ${ }^{19}$

English, on the other hand, always projects the EPP position of Tense where both thematic and non-thematic subjects appear at PF. Thus, the difference between the two languages is argued to be the possibility of two subject positions in Greek but only one in English and the obligatory EPP-feature on T/AGR in English but not in Greek. How are these differences between the two languages accounted for? On standard assumptions, nominative case in English is one of the features checked in the EPP position, being a property associated with Tense (Chomsky 1995). Other languages, like Greek and Spanish, dissociate nominative case from the preverbal EPP position. Zubizarreta (1999:234) suggests the following generalisation:

(21) If Nom case is distinctive in a given language, it may be borne by a functional projection distinct from the functional category that carries the tense feature.

In (21), 'distinctive' is used as a morphological term. In Greek, the distinctive status of nominative case is uncontroversial. Based on (21), nominative case in Greek can be associated with a functional category other than Tense. Alternatively, (21) could be modified to allow nominative, being distinctive in Greek, to be either inherent or default (cf. Philippaki-Warburton 1989; Tsimpli 1990; Alexiadou 1995). ${ }^{20}$ It is inherent in contexts where the subject appears either in SpecTP or in the postverbal position, assuming the 'discontinuous subject' view (Spyropoulos 2000). Default nominative is associated with DPs which appear in the periphery of the clause, i.e. in a topicalised, dislocated, non-operator position. Default nominative is not exclusively associated with subjects but with objects, quirky subjects or indirect objects as well (see references above).

In summarising, two points are crucial: first, that in Greek but not in English, the EPP position appears depending on whether Tense is specified (dependent or independent) which in turn is due to the dissociation of nominative case and the subject position from the tense structure (see also Chomsky 1998, 1999 for the dissociation between case/agreement and the EPP property). ${ }^{21}$ Secondly, that (null) expletives are subjects in the SpecTP1 position, i.e. the EPP position, only. The implication from these suggestions is that Greek gerund clauses which lack TP1 would fail to project an EPP- or a topic position for subjects in TP1; therefore, neither expletives nor preverbal subjects would be possible in these contexts. 
Apart from the thematic/non-thematic difference which is assumed for the two Greek subject positions, I would like to suggest that a further difference is relevant. Recall that the agreement features are specified in the $\mathrm{T}$ position (Chomsky 1995). In its absence, agreement is not syntactically present in the clause. Recall that FI on null subjects is met provided identification is possible at the sentence level. If this is correct, how is identification of a null subject in the Greek gerund clause met?

In addressing this question we need to consider the interpretive possibilities of subjects in gerunds. In (17c) the interpretation of the null subject in the gerund is obligatorily identical to the subject of the matrix clause. When the subject in the gerund clause is overt, the reference can be disjoint as shown by (17a) above. If 'control' of the null subject by the matrix subject is what is involved in $(17 \mathrm{c})$, it should be an instance of optional control presumably due to the adjunct status of the clause (Williams 1992). Notice however that this 'controlled' interpretation is also found in other adjunct clauses which are fully inflected for agreement:

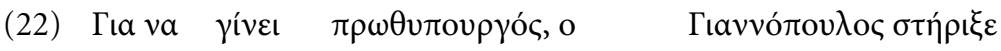
ja na jini proӨipuryos o janopoulos stirikse for suв become PrimeMinister the-Nom Janopoulos supported

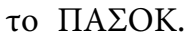
to PASOK the PASOK 'To become Prime Minister, Janopoulos supported PASOK'

(22) cannot be interpreted as somebody other than Janopoulos being the subject of the adjunct clause. If control of a PRO subject is also involved here, the presence of agreement in the adjunct clause has to be considered insufficient for identification. If an overt subject is present, the sentence is still grammatical. I will assume that the 'controlled' interpretation of the null subject is not the result of a syntactic control structure but is pragmatically-conditioned as has been suggested by Philippaki-Warburton \& Catsimali (1999).

Note that the lack of a clause-internal (e.g. spec-head) process of identification for the null subject in the gerund clause as well as in adjunct clauses like (22), distinguishes it from other null subjects of matrix or embedded clauses which lack the 'controlled' interpretation as well as those that require it for reasons to do with the semantics of the matrix predicate. What we should expect then is that the null subject may, in certain cases, be distinct from the subject of the matrix clause. Consider the example in (23): 


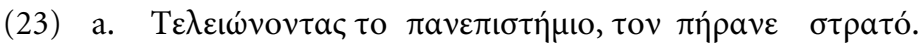
telionondas to panepistimio ton pirane strato finishing the university him took-3PL army 'When he completed his studies, they took him to the army.'

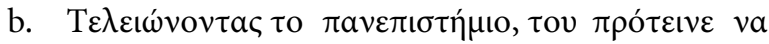
telionondas to panepistimio tu protine na finishing the university him suggested to

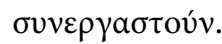
sineryastun work-together 'When he finished his studies, he suggested to him to work together.'

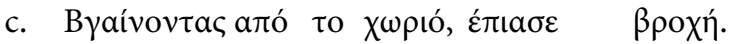
vjenondas apo to xorjo epjase vroxi leaving from the village, started-3sg rain 'When we/you/they left the village, it started to rain.'

In (23a), the subject of the matrix clause is null with non-specific reference. The subject of the gerund is understood to be coreferential with the object of the matrix clause. In (23b), the subject of the gerund can co-refer either with the subject or the object of the matrix clause. In (23c), the subject of the gerund requires an antecedent specified in the preceding discourse given that the thematic structures of the two predicates are not compatible. Overall then, the examples in (23) support the absence of a syntactic control relation between the matrix subject and that of the gerund clause.

Note that in all of these examples there is no overt subject expressed in the matrix clause. If the matrix subject is overt, its position appears to affect the preferred interpretation of the subject of the gerund, as shown in the examples below:

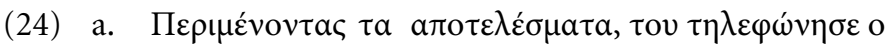
perimenondas ta apotelesmata tu tilefonise $o$ waiting the results his telephoned the-Nom

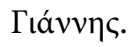
janis Janis 'While waiting for the results, Janis telephoned him.'

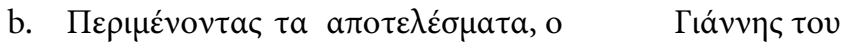
perimenondas ta apotelesmata o janis tu waiting the results the-Nom Janis his 
$\tau \eta \lambda \varepsilon \varphi \omega ́ v \eta \eta \varepsilon$.

tilefonise

telephoned

'While waiting for the results, Janis telephoned him.'

In (24b) where the subject of the matrix clause is preverbal the preferred interpretation for the null subject is 'Janis'; in (24a) on the other hand, the object rather than the postverbal subject is preferred. ${ }^{22}$ On the basis of the data in (23) and (24) we can conclude that null subjects of gerund clauses can be pragmatically controlled by subjects, objects or salient discourse antecedents. At the same time, the preverbal subject of the matrix clause appears to be the default choice of the controller when it appears in the preverbal position. I will assume that in this position, the topic position in SpecTP1, the subject is both thematically and structurally highest in the hierarchy of possible antecedents for the null subject (cf. Grimshaw 1990).

A final point with regard to the interpretation of null subjects in gerund clauses: consider the following examples including gerunds unambiguously interpreted as 'manner' adverbials:

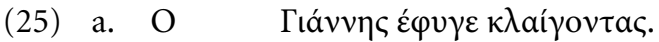

o janis efije kleyondas

the-NOM Janis left crying

'Janis left crying.'

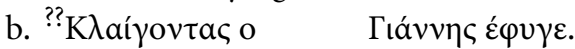

??kleyondas o janis efije

crying the-Nom Janis left-3sg

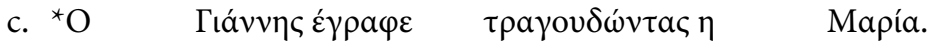

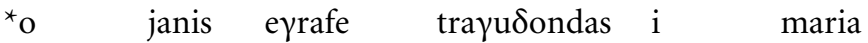

the-nOM Janis was-writing singing the-NOM Maria

'Janis was writing while Mary was singing.'

Manner gerunds obligatorily require coreferentiality between the two subjects (cf. $(25 \mathrm{a} \& \mathrm{c})$ ) and are marginal in clause-initial position. It appears that manner gerunds are VP-adverbial expressions and as such they appear adjoined to the VP-position. Their tense and agreement deficiency as well as their low VP-adjoined position prevents them (a) from having an independently identified subject and (b) from being ambiguous with regard to their temporal interpretation. The first point implies that all other gerunds discussed so far are adjoined higher than the VP level, possibly to some inflectional projection of the matrix clause since their subjects can be overt and/or disjoint 
in reference from the matrix subject. According to the generalisation in (b), namely the lack of ambiguity in temporal readings in manner but not other gerunds, the adjunction site of all but manner gerunds is plausibly the TP1 position of the matrix clause for reasons that have to do with Full Interpretation. Assuming, along with Hornstein (1990), that temporal structure correlates at some syntactic level with clause structure, the underspecification of the E/R relation and the absence of an $S$ point in gerunds requires them to be syntactically linked with the temporal structure of the matrix clause. In fact, although temporally interpreted gerunds discussed above may denote an event contemporaneous with that of the matrix clause, the event denoted by a manner gerund is understood as having a closer relation with the matrix event; it seems that there is a single event denoted compositionally by the activity in the manner gerund and the matrix verb. I assume that in this case the gerund is like a secondary predicate which is interpreted compositionally with the main predicate. This compositionality is compatible with what appears to be an obligatory control structure.

Overall then, reference of the null subject of the gerund is not a matter of identification via agreement as is the case with null subjects in finite clauses. Instead, the null subject merged in its argument position within $\mathrm{vP}$ fails to be associated with formal features in the absence of a TP1 projection. When the null subject of the main clause is a potential 'controller', i.e. it is not an expletive, and its thematic and lexical properties (e.g. animacy) are compatible with those of the gerundive predicate, it is the preferred option. When the subject of the gerund is overt, its interpretation is distinct from the subject of the main clause. ${ }^{23}$

On the basis of the above, let us consider the status of the Greek gerund. The structure in (15) above provides a partial representation of the gerund clause which includes the $\mathrm{vP} / \mathrm{VP}$ domain as well as the Perf position where the auxiliary $\varepsilon \chi \omega$ exo 'have' moves to; in the absence of this auxiliary the verb moves to this position where aspect, i.e. $\mathrm{E}$ and reference time, $\mathrm{R}$ are related. This structure does not represent subjects and also fails to address the question of the categorial feature that the -ondas form has.

I will assume that the -ondas form is a Mood category independently found in Greek subjunctive, indicative and imperative clauses (Drachman \& Klidi 1992; Rivero 1994). Mood is an inflectional category lacking Tense and Agreement features which, in non-gerund clauses, are independently specified in the TP1 projection. Notice also that the Mood category does not have an EPP- or a p- (topic) feature since the former is related to the tense/modal structure and the latter to the layer of clause structure which can host Operators or topics (but 
see Drachman \& Klidi 1992). Thus, subjects, topics, focused and wh-elements are excluded from this position.

Negative gerunds are introduced by the negator $m i$ which is the negator found in non-indicative clauses. ${ }^{24}$ I will assume that as in the case of negative subjunctives, the Mood category selects the negator mi (cf. Philippaki-Warburton 1989, 1994; Tsimpli 1990). The structure of the gerund has now the following form:

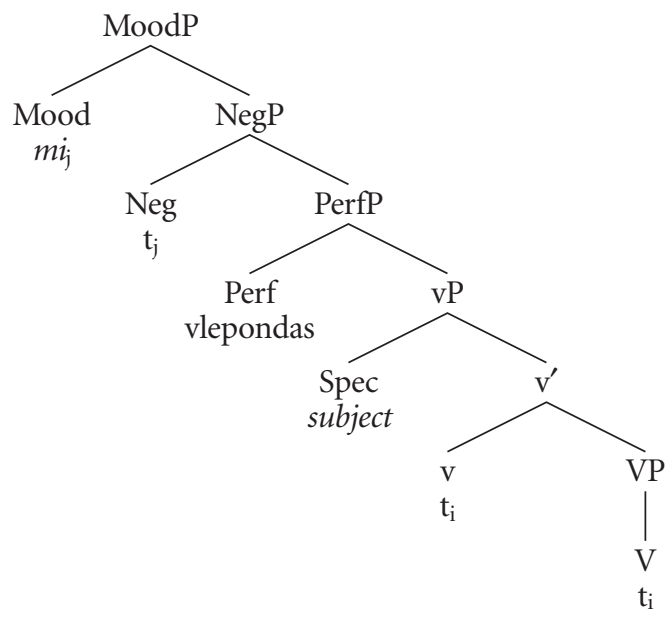

Movement of the gerund to Mood is blocked by the negator although the mi+V-ondas order is grammatical, unlike negative imperatives (PhilippakiWarburton 1994; Philippaki-Warburton \& Spyropoulos 1998). Even if we assume that the negator is affixal, movement would give rise to the wrong order on the assumption that left-adjunction is the only choice (Kayne 1994). As shown by the structure in (26), in negative gerunds the verb moves only up to Perf. The gerundive feature marked on the Mood projection, responsible for clause-typing, requires overt realisation. I will assume that in the presence of the negator, the requirement for overt realisation is met by movement of the negator to Mood (see Manzini \& Savoia 1999 for Arberësh and Roussou 2000 for Greek). This is consistent with the properties of the $m i(n)$ negator which are closely associated with the mood feature [-indicative] of the clause in which it occurs.

With regard to the movement of the auxiliary 'have' to the Perf position, there appear to be two problems with this assumption. First, it was argued above that this position includes aspectual features as these are related to Reference time. In the perfect, the aspectual features are specified on the matrix verb and not on the auxiliary itself (cf. Alexiadou 1997; Xydopoulos 1999). Secondly, the Perf position cannot be argued to be $[+\mathrm{V},-\mathrm{N}]$ since the E/R 
relation can be specified on participles which have nominal features, such as the ones in (27) below.

With regard to the first objection, I assume that the verbal aspectual features are shared by the auxiliary in the Perf position on the grounds that they belong to the same head-dependency (Manzini 1995). In this sense the Aux $+\mathrm{V}$ element has the properties of a discontinuous element, although no headmovement is argued to take place. As for the second objection, notice that the participles in question can also appear with nominative subjects:

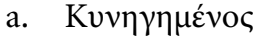

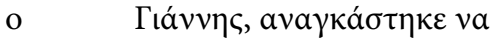
kinijimenos
o janis
janis anagastike na
persecuted-MASC.SG.NOM the-NOM Janis
was-forced sUB J
$\beta \rho \varepsilon ı$ катафúүıاo.
vri katafijio
find refuge

'John being persecuted, he was forced to find refuge.'

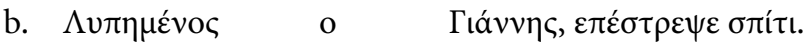
lipimenos o janis epestrepse spiti
sad-MASC.sG.NOM the-NOM Janis returned home
'John being sad, he returned home.'

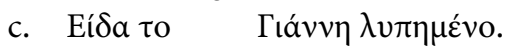

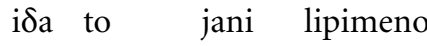

saw the-ACC Jani sad-ACC

'I saw Jani sad.'

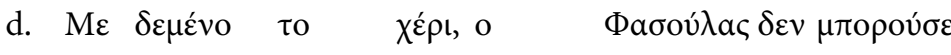

me $\delta$ emeno to xeri o fasulas $\delta$ en boruse

with bandaged the-ACc hand the-Nom Fasulas not was-able

va $\pi \alpha^{\prime} \xi \varepsilon l$.

na peksi

SUBJ play-3sg

'With his hand bandaged, Fasoulas could not play.'

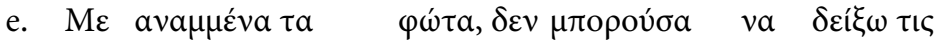

me anamena ta fota $\delta$ en borusa na $\delta$ ikso tis

with lit the-ACc lights not was-able-1sg subj show the

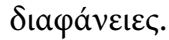

Sjafanies

transparencies

'With the lights on, I wasn't able to show the transparencies.' 
(27a\&b) are examples of adjunct participial clauses with the passive participle clearly marked for nominal features and nominative case. (27c-e) are not relevant to the discussion: $(27 \mathrm{c})$ includes a participle as a predicate of a small clause which is the complement of the perception verb 'to see'. (27d\&e) show the adjunct participle to be introduced by the preposition me ('with') and bearing accusative case.

Assuming that (27a\&b) include a covert ondas (i.e. the gerund form of the verb ime 'to be'), responsible for the categorial status of the clause, we expect the distribution of these adjunct participial clauses to be similar to that of gerunds discussed so far. This is the wrong prediction insofar as disjoint reference between the matrix subject and the subject of the participle is concerned. In particular, in nominative adjunct participles such as $(27 \mathrm{a} \& \mathrm{~b})$ the subject of the matrix clause has to be coreferential with the nominative subject on the participle. Disjoint reference leads to ungrammaticality:

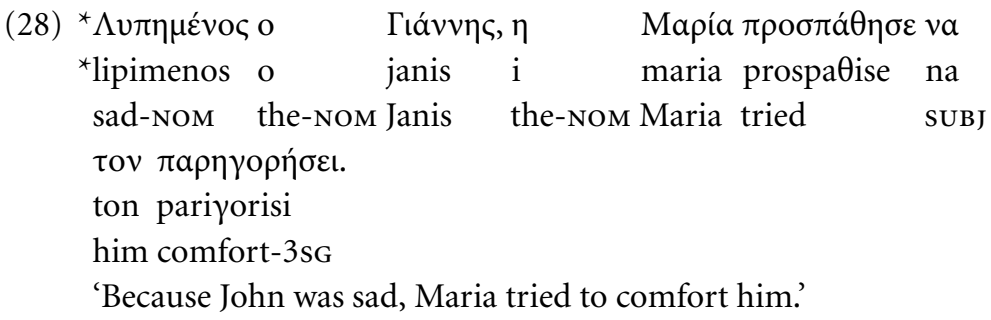

The unavailability of disjoint reference can be argued to imply that, although the 'ondas' MoodP is present, the representation is different from gerunds. The difference then should be sought elsewhere, and, specifically, in the Voice feature on the verb. The -menos participles are passive while gerunds bear active voice features. ${ }^{25}$ Both include a Perf phrase since the $\mathrm{E} / \mathrm{R}$ relation is specified, in the -menos participles as being necessarily E_R. Building on Chomsky's (1995) idea that $\mathrm{vP}$ is absent in passive or unaccusative structures, I will assume that this projection is missing in these participial clauses. If this is correct, then neither of the two subject positions argued for above is available in -menos adjunct structures and only a PerfP is projected which differs from the PerfP of the gerund, or other finite (perfect) clauses, in that it is a $[+\mathrm{N},+\mathrm{V}]$ category.

Note finally that the interpretation of participial adjunct clauses differs from that of gerunds in that the former allow for a 'manner' or a 'cause' interpretation but never a temporal one. This difference implies first that there is no need for temporal mapping at the sentence structure level and secondly that the participial clause is adjoined at the VP level. 


\section{Conclusions}

In this paper some of the basic properties of Greek gerunds have been examined with the aim of identifying their structural position in the sentence as well as their internal structure. With regard to their structural position, it is argued that gerunds adjoin to the higher tense projection of the matrix clause, for reasons that have to do with Full Interpretation of tense. Gerunds are deficient in temporal structure, in that they lack a tense/agreement projection while the anterior or contemporaneous interpretation with regard to the event of the matrix clause is specified on the temporal/aspectual projection, T2 in Giorgi and Pianesi's terms. Regarding subjects, gerunds are argued to involve either null subjects which are pragmatically controlled or overt subjects with disjoint reference. In the first case, the 'controlled' interpretation is argued to be related to the question of thematic and structural prominence as this is expressed by a preverbal subject. Since gerunds lack a tense/modal structure and agreement, null subjects fail to be identified in the usual way. The lack of expletive or preverbal subjects is argued to stem from the lack of the tense projection which, in Greek, has a p- (topic) and an EPP-feature. Thus, preverbal subjects, when thematic, are topics whereas non-thematic or generic subjects are EPP-subjects lacking a lower subject position.

\section{Notes}

* A part of this paper was presented at the 14th International Symposium on Theoretical and Applied Linguistics, in Thessaloniki. I am grateful to Irene Philippaki-Warburton, Anna Roussou, Neil Smith and Tasos Tsangalidis for their helpful comments. All errors remain my own.

1. I haven't included negative gerunds in the examples in (1). It is worth pointing out that they tend to have a causative interpretation. However, at the same time, there is a temporal reading associated with the cause preceding the event of the matrix clause. As such, they do not constitute a counterexample to the generalisation.

2. Agreement is marked by the (default) neuter in clausal nominalisation given that the complement of D, i.e. the CP, is not a nominal category and so it lacks inherent agreement features. In such cases, D bears case features only. Nominalisation is also found with other categories, e.g. adverbials as shown by the examples below:

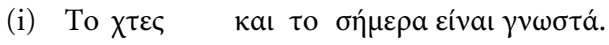

to xtes ke to simera ine $\gamma$ nosta

the yesterday and the today are known

'We know about yesterday and today.' 
However, other adverbs like 'often', 'completely' etc. can only be introduced by a definite article when 'mentioned' rather than 'used' (see note 3 ).

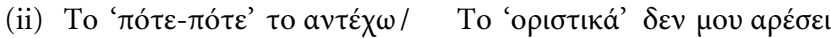

to 'pote-pote' to andexo/ to 'oristika' $\delta$ en mu aresi

the 'sometimes' it accept-1sG/the 'definitely' not me please-3sG

Although these are marked contexts, it is noteworthy that other languages, e.g. English, fail to use the definite D in 'mention' as in (ii) above.

3. Nominalised clauses are also found in adjunct prepositional phrases in which the $\mathrm{CP}$ has to be nominalised since the preposition is a case-marking one (see also Joseph 1979, 1990):

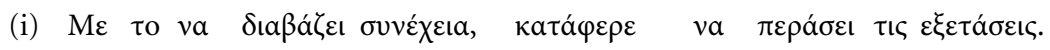
me to na Sjavazi sinexia katafere na perasi tis eksetasis

with the suBj read-3sg continously managed-3sg SUBJ pass-3sg the exams

'By reading all the time, he managed to pass the exams.'

4. The use of the (expletive) definite article introducing almost any element, including adjunct clauses, is found in highly marked contexts which involve the 'use-mention' distinction. For example, in (i) the adjunct clause is preceded by the definite article but its structure or content is totally opaque to the representation:

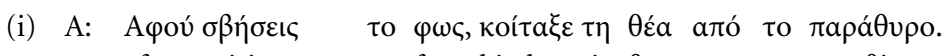

afu svisis to fos kitakse ti $\theta$ ea apo to paratiro

after turn-off-2sg the light look the view from the window

'After you turn-off the light, look at the view from the window.'

$B$ looks out of the window without switching off the light and sees nothing.

Then he remembers and says:

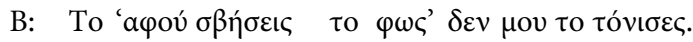

to 'afu svisis to fos' $\delta$ en mu to tonises

the 'after switch-off the light' not me it pointed-out-2sG

'You didn't emphasize the "after you switch-off the light".'

Note that the definite article is obligatory in these cases, since it is linked to an argument position. However, the material included between the quotes is totally irrelevant to the syntactic computation and interpretation.

5. Even if we assume that subject clauses are obligatorily nominalised because they appear in a peripheral position (and not the subject position) their obligatory nominalisation indicates that their co-indexation with a pro subject is possible provided they are case-marked. The inability of gerunds becoming nominalised still holds in that it indicates their non-CP status, hence their incompatibility with nominalisation.

6. Some speakers consider local movement, i.e. the wh- or focus object preceding the gerund, acceptable. For example, Tsoulas (1996) suggests that although wh-movement out of gerunds is marginal it is not unacceptable compared to wh-movement out of participial forms, illustrating with examples such as the following:

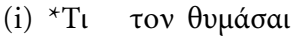

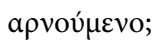
${ }^{*}$ ti ton $\theta$ imase
arnoumeno?
what him remember-2sG refuse-3sG.MAsc.ACC 
Although I agree with Tsoulas' judgements on participles, I disagree with him on his judgements on $w h$-movement out of gerunds. It is worth pointing out that examples such as (i) above involve long-distance movement rather than local. In (ii) the example improves since the $w h$-phrase has an echo interpretation (as such it cannot be considered relevant to the question of syntactic wh-movement):

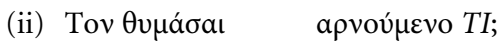

ton $\theta$ imase arnumeno TI?

him remember-2sg refusing what

In all of Tsoulas' examples with gerunds, the wh-phrase precedes but is adjacent to the gerund, thus allowing, in my view, the echo interpretation similarly with (ii) above. I assume that for these speakers the echo reading can be associated with the pre- and postgerund position but always within the gerund clause.

7. Again, according to a reviewer, there appear to be counterexamples with gerunds having a conditional (and possibly generic) reading:

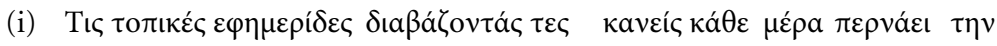

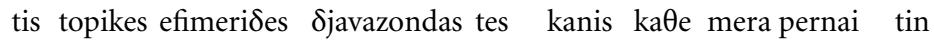
the local newspapers reading them one every day pass-3sg the

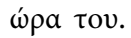

ora tu

time his

'Reading local newspapers every day, you can pass your time easily'.

I believe that there are various factors which improve this sentence in comparison with the data in (13); the specificity of the topicalised constituent (which is not guaranteed with the definite article and the noun only), and the generic reading of the sentence (shown by the use of the indefinite 'kanis'), for example. How these factors affect acceptability is an interesting question which, however, I will not address here.

8. Rivero (1994) argues that preverbal subjects are possible in gerund clauses. Assuming that the preverbal position is a topic position, the data in (13) imply that subjects and objects occupy a different topic position. Rivero's structure of gerunds with preverbal subjects includes the subject in SpecMP, the -ondas form occupying the head position. I will return to subjects in following sections.

9. This 'non-finite' form is not a participle since it also lacks nominal features (but see Joseph 1983:80) who argues for the participial status of forms like $\gamma \rho \alpha \dot{\alpha} \psi \varepsilon / / \gamma \rho \alpha \varphi \tau \varepsilon i ́$ rapsi/ $\gamma$ rafti ('written, been-written') on the grounds that the paradigm otherwise lacks perfective participles; note, however, that Joseph contrasts these with the -ondas forms which he considers imperfective participles. On the analysis developed here neither $\gamma \mathrm{rapsi} / \gamma \mathrm{rafti}$ nor the -ondas forms are considered participial; (see also Holton et al. 1997). An apparent problem with assuming that the form is perfective concerns the fact that this form is not involved in a binary opposition with a non-finite imperfective form. Recall that the imperfective morphology of the Greek gerund was argued not to be specified in its feature matrix given that both perfective and imperfective readings are possible and also that the imperfective is the unmarked member of the paradigm in this language. Thus, although the 
non-finite form in the perfect is not contrasted with an imperfective one, it is specified as perfective on the basis that it is the 'marked' form in the language.

10. Smith (1989) argues for the pragmatic function of the 'have' auxiliary in present perfect, instructing the listener to access a present context. Thus for Smith a complete analysis of the perfect requires consideration of linguistic and pragmatic factors.

11. Note that neither Hornstein (1990) nor Giorgi and Pianesi (1991) consider aspectual information as being associated with the E position. Giorgi and Pianesi include aspectual features in T2 although they claim that this is a tense rather than an aspectual projection.

12. The $\mathrm{E} \_\mathrm{R}$ relation can also be unambiguously specified in the gerund clause by the use of a temporal or aspectual adverbial:

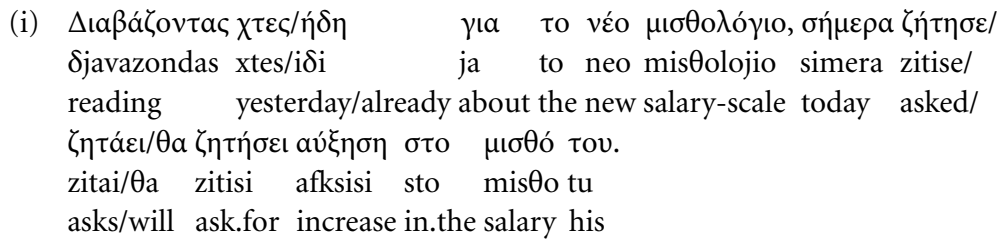

I assume that the adverbial appears in the specifier of the PerfP where it becomes responsible for fixing the E/R relation as $\mathrm{E} \_\mathrm{R}$. Further movement of the -ondas form is required for the derivation of the surface order (see Section 3).

13. This suggestion apparently violates the Biunique Mapping Principle since the absence of morphological realisation does not prevent the projection of PerfP. However, the suggestion is compatible with the idea that the availability of a binary opposition between perfect and non-perfect gerunds justifies the projection of the relevant functional category, although it does not endow it with specified features in the absence of morphological realisation bearing these features.

14. The lack of the posterior reading is also attested in English 'bare' gerunds, i.e. in gerunds of the nominative absolute construction. The lack of tense specification and the absence of the gerund presumably constrain the temporal options to the antecedent or simultaneous as in Greek gerunds.

15. Simple tensed forms in the indicative (with the exception of the aorist) and tensed or untensed subjunctive forms are compatible with a modal reading (cf. Tsangalidis 1999; Tsimpli \& Roussou 1996).

16. Other non-modal readings with reference to past and present are also excluded due to the absence of any tense realisation in gerund clauses. It should also be noted that future readings are available in the absence of any modal specification:

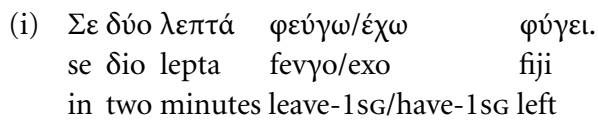

However, in these cases there is a full tense structure and the $\mathrm{R}$ point is shifted in the presence of the prepositional phrase. As a reviewer points out, the past, perfective form generally resists the future interpretation with very few lexical exceptions, e.g. se dio lepta 
efiya (lit. 'in two minutes, I left') (see also Tsimpli \& Roussou 1996 for the claim that the Greek past-perfective is truly deictic).

17. Some weather verbs, however, do allow for gerunds:

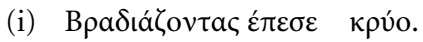

vraסiazondas epese krio

getting-dark fell-3sg cold

'When it got dark, it became cold.'

It is possible that these verbs assign a thematic role of some sort which is the undergoer of a 'process'. Note that in English, such weather verbs disallow overt expletives when in the gerundive form, unlike the English examples in (19).

18. Why overt subjects, referential or expletive, are not allowed in gerunds with connectives is a separate question that has received alternative explanations (Reuland 1983; Safir 1985). On one hand, connectives are supposed to lack case-assigning properties and on the other, their presence 'absorbs' the governing property of -ing or INFL which can assign case to the overt subject (cf. Reuland 1983).

19. EPP-subjects may include subjects of stative verbs which seem to disallow non-SVO orders (Alexiadou 1995, 1999).

20. Zubizarreta's (1999) suggestion is that in Spanish, nominal and verbal features of Tense are split in the structure projecting a $T_{N}$ and a $T_{V}$ independently. This is presumably a parametric difference since in languages like Italian or English Tense projects as a single category with both types of features.

21. Bare plural subjects are required to be necessarily postverbal. Although the TP1 projection should be available in these cases, agreement features also being present, the position of the overt subject is restricted. I assume that the reason has to do with the preverbal position imposing requirements on the status of the subject (being a DP or richer projection but not an NP).

22. According to Rizzi (1987), a postverbal subject in Italian cannot control the subject of a gerundive adjunct clause, whereas in Spanish either pre- or postverbal matrix subjects give grammatical results (Zubizarreta 1999). Note that Greek patterns with Spanish in that postverbal subjects are possible 'controllers' although the preferred position for the subject 'control' interpretation is the preverbal one.

23. Following Chomsky $(1995,1998)$ I assume that phi-features on the noun are interpretable and do not trigger or require checking.

24. As noted in n.1, negative gerunds tend to have a causative reading. This is also the tendency in the interpretation of English gerunds (Neil Smith, p.c.). I will assume that the cause reading is pragmatically rather than morphosyntactically derived as is the case with many of the possible interpretations of gerund clauses. Needless to say, an analysis of the pragmatic factors which lead to the variety of interpretations of gerunds is required; it is however beyond the scope of this paper.

25. Clearly, I do not include deponent verbs in this discussion; their 'passive' form does not imply syntactically passive behaviour. 


\section{References}

Agouraki, Yoryia. 1990. "On the Projection of Maximal Categories: The Case of CP and FP in Modern Greek”. UCL Working Papers in Linguistics 2.183-199.

Alexiadou, Artemis. 1995. "Subject Positions in Modern Greek". Studies in Greek Linguistics 16.242-253.

Alexiadou, Artemis. 1997. Adverb Placement: A Case Study in Antisymmetric Syntax. Amsterdam \& Philadelphia: John Benjamins.

Alexiadou, Artemis. 1999. "On the Properties of Some Greek Word Order Patterns". Alexiadou, Horrocks \& Stavrou 1999. 45-65.

Alexiadou, Artemis, Geoffrey Horrocks \& Melita Stavrou, eds. 1999. Studies in Greek Syntax. Dordrecht, Boston, London: Kluwer Academic Publishers.

Alexiadou, Artemis \& Elena Anagnostopoulou. 1998. "Parametrizing Agr: word-order, V-movement and EPP-checking". Natural Language and Linguistic Theory 16. 491-539.

Anagnostopoulou, Elena. 1994. Clitic Dependencies in Modern Greek. Ph. D. Dissertation, Universitaet Salzburg.

Belletti, Adriana. 1990. Generalised Verb Movement. Turin: Rosenberg \& Sellier.

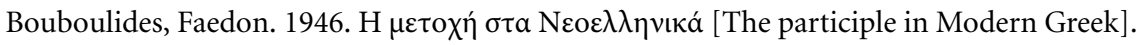
Athens.

Chomsky, Noam. 1995. The Minimalist Program. Cambridge, Mass.: MIT Press.

Chomsky, Noam. 1998. "Minimalist inquiries: the framework”. Ms., MIT.

Chomsky, Noam. 1999. "Derivation by Phase”. Ms., MIT.

Christidis, A.-Ph. 1986. “The Morpheme $p u$ as a Definite Clause Nominaliser” [in Greek]. Studies in Greek Linguistics 7.135-148.

Comrie, Bernard. 1976. Aspect. Cambridge University Press.

Drachman, Gaberell \& Sila Klidi. 1992. “The Proper Treatment of Adverbial Questions in Greek: The Extended Minimal Structure Hypothesis”. Studies in Greek Linguistics 13.371-389.

Giorgi, Alessandra \& Fabio Pianesi. 1991. “Toward a Syntax of Temporal Representations”. Probus 2. 187-213.

Giorgi, Alessandra \& Fabio Pianesi. 1997. Tense and Aspect: From Semantics to Morphosyntax. Oxford University Press.

Grimshaw, Jane. 1990. Argument Structure. (= Linguistic Inquiry Monograph Eighteen). Cambridge, Mass.: MIT Press.

Holton, David, Peter Mackridge \& Irene Philippaki-Warburton. 1997. Greek: A Comprehensive Grammar of the Modern Language. London \& New York: Routledge.

Hornstein, Norbert. 1990. As Time Goes By: Tense and Universal Grammar. Cambridge, Mass.: MIT Press.

Horrocks, Geoffrey. 1994 "Subjects and Configurationality”. Journal of Linguistics 30. 81-109. Joseph, Brian D. 1979. "Raising to Oblique in Greek". Proceedings of the Fifth Meeting of the Berkeley Linguistics Society, 114-128.

Joseph, Brian D. 1983. The Synchrony and Diachrony of the Balkan Infinitive. Cambridge University Press. 
Joseph, Brian D. 1985. "Complementisers, Finiteness and Particles in Greek and the Balkans”. Folia Slavica 7:3.390-411.

Joseph, Brian D. 1990. "Is Raising to Prepositional Object a Possible Grammatical Rule?" Studies in Relational Grammar 3, ed. by Paul M. Postal \& Brian D. Joseph, 261-276. Chicago: University of Chicago Press.

Kayne, Richard S. 1994. The Antisymmetry of Syntax (= Linguistic Inquiry Monograph Twenty-Five). Cambridge, Mass.: MIT Press.

Manzini, Maria-Rita. 1995. "From Merge and Move to Form Dependency". UCL Working Papers in Linguistics 7. 323-345.

Manzini, Maria-Rita \& Leonardo Savoia. 1999. "The Syntax of Middle-Reflexive and Object Clitics: A Case of Parametrization in Arberësh Dialects”. Studi in onore di Luigi Marlekaj ed. by M. Mandalà, 328-383. Bari: Adriatica.

Philippaki-Warburton, Irene. 1985. "Word-Order in Modern Greek". Transactions of the Philological Society 2.113-143.

Philippaki-Warburton, Irene. 1987. "Empty Categories and the pro-drop Parameter in Greek”. Journal of Linguistics 23.289-318.

Philippaki-Warburton, Irene. 1989. "Subject in English and Greek". Proceedings of the 3rd Symposium on the Description and/or Comparison of English and Greek, 11-32. Thessaloniki: Aristotle University of Thessaloniki.

Philippaki-Warburton, Irene. 1994. "Verb Movement and the Distribution of Clitics" [in Greek]. Studies in Greek Linguistics, 892-905. Thessaloniki.

Philippaki-Warburton, Irene \& Vassilios Spyropoulos. 1998. "On the Boundaries of Inflection and Syntax". Proceedings of the First Mediterranean Conference on Morphology ed. by Geert Booij, Angela Ralli \& Sergio Scalise, 215-226. Patras: University of Patras. Philippaki-Warburton, Irene \& Georgia Catsimali. 1999. “On Control in Greek”. Alexiadou, Horrocks \& Stavrou, 1999. 153-168.

Philippaki-Warburton, Irene \& Vassilios Spyropoulos. 1999. “Agreement and EPP in Greek:

The Discontinuous Subject Hypothesis”. Ms., University of Reading.

Reichenbach, Hans. 1947. Elements of Symbolic Logic. New York: Free Press.

Reuland, Eric. 1979. Principles of Subordination and Construal in the Grammar of Dutch.

Ph.D. Dissertation, Groningen University.

Reuland, Eric. 1983. "Governing -ing”. Linguistic Inquiry 14:1. 101-136.

Rivero, Maria-Luisa. 1994. "The Structure of the Clause and V-Movement in the Languages of the Balkans". Natural Language and Linguistic Theory 12. 63-20.

Rizzi, Luigi. 1982. Issues in Italian Syntax. Dordrecht: Foris Publications.

Roussou, Anna. 1991. "Nominalised Clauses in the Syntax of Modern Greek". UCL Working Papers in Linguistics 3. 77-100.

Roussou, Anna. 1994. The Syntax of Complementisers. Ph. D. Dissertation, University College London.

Roussou, Anna. 1999. "Modals and the Subjunctive”. Alexiadou, Horrocks \& Stavrou 1999. $169-183$.

Roussou, Anna. 2000. “On the Left Periphery: Modal Particles and Complementisers”. Ms., University of Cyprus.

Safir, Kenneth J. 1985. Syntactic Chains (= Cambridge Studies in Linguistics, 40). Cambridge University Press. 
Smith, Carlota S. 1991. The Parameter of Aspect (= Studies in Linguistics and Philosophy, 43). Dordrecht, Boston, London: Kluwer Academic Publishers.

Smith, Neil. 1989. The Twitter Machine: Reflections on Language. Oxford \& Cambridge, Mass.: Basil Blackwell.

Spyropoulos, Vassilios. (2000). Agreement Relations in Greek. Ph. D. Dissertation, University of Reading.

Stowell, Tim. 1982. “The Tense of Infinitives”. Linguistic Inquiry 13:3.561-570.

Stowell, Tim. 1992. "Syntax of Tense”. Ms., UCLA.

Terzi, Arhonto. 1992. PRO in Finite Clause: A Study of the Inflectional Heads of the Balkan Languages. Ph. D. Dissertation, CUNY.

Tsangalidis, Anastasios. 1999. Will and Tha: A Comparative Study of the Category Future. Thessaloniki: University Studio Press.

Tsimpli, Ianthi Maria. 1990. “The Clause Structure and Word Order of Modern Greek". UCL Working Papers in Linguistics 2.226-255.

Tsimpli, Ianthi Maria. 1992/1996. The Prefunctional Stage of First Language Acquisition: a Crosslinguistic Study. New York: Garland.

Tsimpli, Ianthi Maria. 1995. "Focusing in Greek”. Discourse Configurational Languages, ed. by Katalin Kiss, 176-206. Oxford University Press.

Tsimpli, Ianthi Maria. 1998. "Individual and Functional Readings for Focus, wh- and Negative Operators: Evidence from Greek". Themes in Greek Linguistics II (= Current Issues in Linguistic Theory, 159), ed. by Brian D. Joseph, Geoffrey C. Horrocks \& Irene Philippaki-Warburton, 197-227. Amsterdam \& Philadelphia: John Benjamins.

Tsimpli, Ianthi Maria \& Anna Roussou. 1996. "Negation and Polarity Items in Modern Greek". The Linguistic Review 13.49-81.

Tsimpli, Ianthi Maria \& Stavroula Stavrakaki. 1999. "A Morphosyntactic Deficit in the Determiner System: The Case of a Greek SLI Child”. Lingua 108.31-85.

Tsoulas, George. 1996. "Notes on Temporal Interpretation and Control in Modern Greek Gerunds". York Papers in Linguistics 17.441-470.

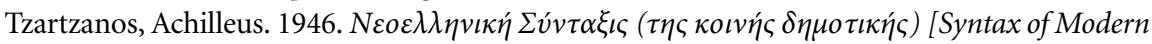
Greek (Standard Demotic), vol.I. Athens.

Varlokosta, Spyridoula. 1994. "The Properties of pu-complements in Modern Greek". Themes in Greek Linguistics, ed. by Irene Philippaki-Warburton, Katerina Nicolaidis \& Maria Sifianou. Amsterdam \& Philadelphia: John Benjamins.

Xydopoulos, George J. 1996. Tense, Aspect and Adverbials in Modern Greek. Ph. D. Dissertation, University College London.

Xydopoulos, George J. 1999. "Tense and Temporal Adverbials in Greek". Alexiadou, Horrocks \& Stavrou 1999. 263-276.

Williams, Edwin. 1992. “Adjunct control”. Control and Grammar, ed. by Richard K. Larson, Sabine Iatridou, Utpal Lahiri \& James Higginbotham, 297-332. Dordrecht, Boston, London: Kluwer Academic Publishers.

Zubizarreta, Maria Luisa. 1999. "Word Order in Spanish and the Nature of Nominative Case”. Beyond Principles and Parameters, ed. by Kyle Johnson \& Ian Roberts, 223-250. Dordrecht, Boston, London: Kluwer Academic Publishers. 


\section{$\Pi \varepsilon \rho i ́ \lambda \eta \psi \eta$}

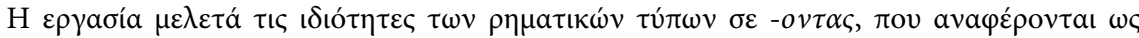

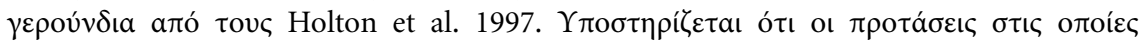

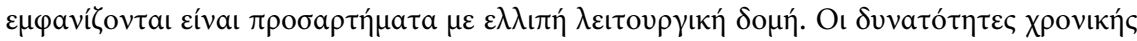

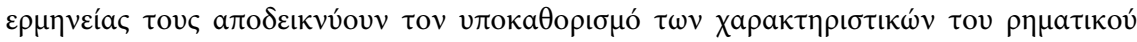

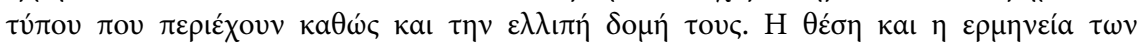

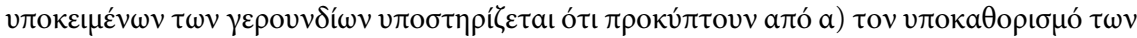

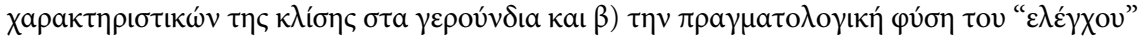

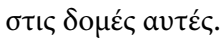

